Original Article

\title{
Study of acceleration of center of mass during sit-to-stand and stand-to-sit in patients with stroke
}

\author{
Eunjin Na, MSc ${ }^{1)}$, Hyesun Hwang, BHSc ${ }^{1)}$, Youngkeun Woo, PhD, $\mathrm{PT}^{2)^{*}}$ \\ 1) Department of Physical Therapy, Dream Hospital, Republic of Korea \\ 2) Department of Physical Therapy, College of Medical Sciences, Jeonju University: 303 Cheonjam-ro, \\ Wansan-gu, Jeonju 560-759, Republic of Korea
}

\begin{abstract}
Purpose] The purpose of this study was to compare the center of mass during sit-to-stand and standto-sit activities in the timed up and go test between healthy subjects and patients with stroke. [Subjects and Methods] Thirty healthy participants and thirty patients with stroke volunteered for this study. Acceleration of the center of mass was measured using a wireless tri-axial accelerometer during sit-to-stand and stand-to-sit activities in the timed up and go test. Accelerometer data were analyzed using BTS G-studio software. [Results] The phase duration was significantly longer and the anterior-posterior, mediolateral, and vertical acceleration ranges were significantly lower during sit-to-stand for patients with stroke than for healthy controls. Further, phase duration and the mediolateral acceleration range during stand-to-sit differed significantly between healthy controls and subjects with stroke. [Conclusions] During training for the sit-to-stand activity, the focus should be all three balance dimensions, but during training for the stand-to-sit activity, the focus should be on improving mediolateral balance and asymmetrical foot positioning should be recommended.

Key words: Center of mass, Sit-to-stand, Stand-to-sit
\end{abstract}

(This article was submitted Mar. 15, 2016, and was accepted May 23, 2016)

\section{INTRODUCTION}

Stroke is one of the most common causes of death in Korea ${ }^{1}$, and most stroke patients experience difficulties with activities of daily living (ADLs) and have spatial and temporal cognitive impairment, communication impairment, and hemiplegia ${ }^{2)}$. In stroke patients with lesions in one hemisphere, hemiplegia can result from weakness of the contralateral upper and lower extremities and weakness of the trunk muscles ${ }^{3}$. Weakness of the lower extremities hampers walking, and the ability to walk is a basic and essential need for conducting ADLs. Therefore, improving a patient's walking ability is an important goal during rehabilitation following stroke ${ }^{4}$. When attempting to walk, hemiplegic patients have excessive lateral motion of their center of mass (COM) and experience a higher ground reaction force with a lower peak torque around the joints, compared to healthy subjects ${ }^{5}$. These characteristics restrict their participation in the community and limit their independence, which negatively affects quality of life 6,7 .

Before they can begin to walk, patients with stroke must first stand from being seated and maintain balance. The COM must be maintained within the base of support (BOS) during mobility while conducting ADLs, but most patients have an asymmetrical posture, poorly performing extremities, and problems with coordination ${ }^{8}$. The timed up and go (TUG) test is commonly used to simultaneously evaluate abilities such as balancing and walking ${ }^{6}$. TUG was originally designed to evaluate balance in elderly people and to examine locomotion mobility for predicting the risk of fall injury, but it can be also used in patients with stroke or arthritis of the lower extremities ${ }^{9)}$.

\footnotetext{
*Corresponding author. Youngkeun Woo (E-mail: ykwoo92@empas.com)

(C)2016 The Society of Physical Therapy Science. Published by IPEC Inc.

This is an open-access article distributed under the terms of the Creative Commons Attribution Non-Commercial No Derivatives (by-nc-nd) License $<$ http://creativecommons.org/licenses/by-nc-nd/4.0/>.
} 
In the present study, the acceleration of the COM during sit-to-stand and stand-to-sit in TUG tests was measured and the performance of healthy subjects was compared with that of patients with stroke.

\section{SUBJECTS AND METHODS}

A total of 60 participants ( 30 healthy subjects and 30 patients with stroke) were enrolled in this study; written informed consent was obtained from all participants. The 30 healthy subjects had no other musculoskeletal, cardiopulmonary, or neuromuscular disorders and no history of any physical therapy in the 6 months prior to recruitment. The following inclusion criteria were set for the subjects with stroke: (1) at least 6 months had elapsed since the stroke, (2) the ability to walk independently for $10 \mathrm{~m}$ with supervision, (3) ability to communicate (score $>24$ on Mini-Mental State Examination), and (4) no secondary complications after the stroke. Prior to recruitment, the study protocol was approved by the Jeonju University Institutional Review Board (jjIRB-151209-HR-2015-1202).

Table 1 describes the general characteristics of the participants (Table 1). Acceleration of the COM was measured using a wireless tri-axial accelerometer (G-Walk; BTS Bioengineering S.p.A., Italy) that was attached to the 5th lumbar vertebra and tightened with Velcro ${ }^{\mathrm{TM}}$ while the participants performed sit-to-stand and stand-to-sit during a traditional TUG test before the participants made initial contact with the ground to start walking. The accelerometer data were wirelessly transferred via a Bluetooth system to a laptop computer and analyzed using BTS G-studio software (BTS Bioengineering S.p.A., Italy). The weight of the accelerometer was $37 \mathrm{~g}$, and its dimensions were $70 \times 40 \times 18 \mathrm{~mm}$. The mean value of three trials was used for data analysis. Phase duration (s), anterior-posterior (AP) acceleration range $\left(\mathrm{m} / \mathrm{s}^{2}\right)$, mediolateral (ML) acceleration range $\left(\mathrm{m} / \mathrm{s}^{2}\right)$, and vertical $(\mathrm{VT})$ acceleration range $\left(\mathrm{m} / \mathrm{s}^{2}\right)$ were calculated on the basis of COM motion during sit-to-stand and stand-to-sit activities.

Descriptive and frequency statistics were used to compare the general characteristics of healthy subjects and patients with stroke, and the independent $t$-test was used to compare the accelerometer data obtained during sit-to-stand and stand-to-sit activities in the TUG test. The $\mathrm{p}$ value was set at 0.05 for all statistical tests.

\section{RESULTS}

The phase duration during sit-to-stand was significantly longer for the patients with stroke than for the healthy subjects $(\mathrm{p}<0.05)$. Further, the AP, ML, and VT acceleration ranges were significantly slower in patients with stroke during sit-to-stand than in the healthy controls $(p<0.001)$ (Table 2). Phase duration $(p<0.05)$ and the ML acceleration range $(p<0.001)$ during stand-to-sit differed significantly between the healthy subjects and patients with stroke. However, no significant differences were found in the AP and VT acceleration ranges during stand-to-sit ( $>0.05)$ (Table 3).

\section{DISCUSSION}

The purpose of this study was to compare the acceleration of the COM during sit-to-stand and stand-to-sit activities in patients with stroke and healthy subjects. According to the results, all parameters during sit-to-stand differed significantly between the participant groups; however, while phase duration and ML acceleration range during stand-to-sit differed significantly between healthy subjects and those with stroke, the AP and VT acceleration ranges did not.

The phase duration during sit-to-stand was substantially longer in the patients with stroke than in healthy subjects. These results indicate that in patients with stroke, weakness in one leg did not allow for adequate contraction to complete the sit-tostand activity. Burnfield et al. ${ }^{10)}$ reported that patients with stroke required more time during sit-to-stand, and by examining the sit-to-stand activity, Carr et al. ${ }^{11)}$ found that these individuals have less paretic leg muscle power. In the present study, patients with stroke took long to complete the sit-to-stand activity because of weakened paretic leg muscles. The acceleration ranges of AP, ML, and VT during sit-to-stand were significantly lower in patients with stroke than in healthy subjects. Roebroeck et al. ${ }^{12}$ reported that the maximal forward velocity is needed by healthy subjects during sit-to-stand, and that the vertical maximum velocity of COM is needed during the middle phase of sit-to-stand ${ }^{13)}$. In the present study, all threedimensional acceleration parameters during sit-to-stand were lower in the patients with stroke than in the healthy subjects, even though patients with hemiplegia had unilateral body weakness. The ML acceleration range is known to be affected by unilateral body weakness, but the AP and VT acceleration ranges were also affected, because the subjects needed to balance in the ML direction of acceleration that defined as rate of changing in velocity during specified time ${ }^{14)}$.

During stand-to-sit, the phase duration and ML acceleration range were significantly lower in patients with stroke than in healthy subjects, but the AP and VT acceleration ranges did not differ between the groups. Generally, stand-to-sit is performed by both gravity and eccentric contraction of the muscles in order to lower the body mass ${ }^{6}$. The lower ML acceleration range and phase duration in the patients with stroke in the present study indicated that an important feature in patients with stroke is unilateral body weakness, which affects ML balancing during stand-to-sit and in turn affects performance time. However, AP and VT acceleration ranges were affected by the force of gravity during stand-to-sit. Chen et al. ${ }^{15)}$ recommend that asymmetrical foot positioning during stand-to-sit is necessary to train the paretic leg muscles in patients with stroke, and that the paretic leg does not provide adequate power to control sitting down. 
Table 1. General characteristics of the participants $(\mathrm{N}=60)$

\begin{tabular}{lcc}
\hline Characteristics & $\begin{array}{c}\text { Healthy } \\
\left(\mathrm{n}_{1}=30\right)\end{array}$ & $\begin{array}{c}\text { Stroke } \\
\left(\mathrm{n}_{2}=30\right)\end{array}$ \\
\hline Gender (N, male/female) & $15 / 15$ & $17 / 13$ \\
Age (yrs) & $22.7 \pm 1.5$ & $52.2 \pm 9.7$ \\
Height (cm) & $170.2 \pm 8.4$ & $166.1 \pm 7.4$ \\
Weight (kg) & $62.8 \pm 14.6$ & $65.8 \pm 9.8$ \\
Onset (month) & $\mathrm{N} / \mathrm{A}$ & $31.8 \pm 23.1$ \\
Etiology (N, infract/hemorrhage) & $\mathrm{N} / \mathrm{A}$ & $22 / 8$ \\
Affected side (N, left/right) & $\mathrm{N} / \mathrm{A}$ & $16 / 14$ \\
BBS & $\mathrm{N} / \mathrm{A}$ & $42.9 \pm 6.7$ \\
TIS & $\mathrm{N} / \mathrm{A}$ & $14.2 \pm 3.3$ \\
FGA & $\mathrm{N} / \mathrm{A}$ & $14.6 \pm 6.3$ \\
\hline
\end{tabular}

Data are presented as mean \pm standard deviation.

BBS: Berg Balance Scale; TIS: Trunk Impairment Scale; FGA: Functional Gait Assessment
Table 2. Comparison of acceleration of center of mass during the sit-to-stand activity between healthy subjects and patients with stroke

\begin{tabular}{lcc}
\hline & $\begin{array}{c}\text { Healthy } \\
\text { controls }\end{array}$ & $\begin{array}{c}\text { Patients with } \\
\text { stroke }\end{array}$ \\
\hline Phase duration $(\mathrm{s})$ & $2.19 \pm 0.39$ & $2.50 \pm 0.58^{*}$ \\
AP acceleration range $\left(\mathrm{m} / \mathrm{s}^{2}\right)$ & $8.02 \pm 1.55$ & $6.62 \pm 1.12^{* *}$ \\
ML acceleration range $\left(\mathrm{m} / \mathrm{s}^{2}\right)$ & $4.83 \pm 1.68$ & $3.25 \pm 1.08^{* *}$ \\
VT acceleration range $\left(\mathrm{m} / \mathrm{s}^{2}\right)$ & $8.00 \pm 2.01$ & $4.49 \pm 0.92^{* *}$ \\
\hline
\end{tabular}

Data are presented as mean \pm standard deviation.

$* * \mathrm{p}<0.001, * \mathrm{p}<0.05$.

AP: Anterior-posterior; ML: Mediolateral; VT: Vertical

Table 3. Comparison of acceleration of center of mass during the stand-to-sit activity between healthy controls and patients with stroke

\begin{tabular}{lcc}
\hline & $\begin{array}{c}\text { Healthy } \\
\text { subjects }\end{array}$ & $\begin{array}{c}\text { Patients with } \\
\text { stroke }\end{array}$ \\
\hline Phase duration $(\mathrm{s})$ & $2.15 \pm 0.42$ & $2.49 \pm 0.69^{*}$ \\
AP acceleration range $\left(\mathrm{m} / \mathrm{s}^{2}\right)$ & $7.44 \pm 1.01$ & $6.93 \pm 1.19$ \\
ML acceleration range $\left(\mathrm{m} / \mathrm{s}^{2}\right)$ & $5.97 \pm 1.60$ & $4.35 \pm 1.47^{* *}$ \\
VT acceleration range $\left(\mathrm{m} / \mathrm{s}^{2}\right)$ & $6.43 \pm 2.25$ & $7.12 \pm 2.51$ \\
\hline
\end{tabular}

Data are presented as mean \pm standard deviation.

$* * \mathrm{p}<0.001, * \mathrm{p}<0.05$.

AP: Anterior-posterior; ML: Mediolateral; VT: Vertical

In clinical settings, the generally recommended and reliable test to examine sit-to-stand ability in patients with stroke involves performing five repetitions of 30-s sit-to-stand activities ${ }^{16)}$. However, only the time taken to perform the activities was examined in this previous study. Considering the disturbed movement fluidity during sit-to-stand in patients with stroke ${ }^{17)}$, analysis across all dimensions can easily be determined using an accelerometer, which is a useful instrument for measuring performance in rehabilitation medicine. Generally, accelerometers are used to evaluate walking performance ${ }^{18,19)}$, but they are also useful for examining sit-to-stand activities ${ }^{20}$.

One of the limitations of this study was that because sit-to-stand parameters were measured during the TUG test, it was difficult to separately measure them because of technical problems during walking and after standing. Therefore, there are some needs for technical supporting between them, but TUG naturally performed sit to standing rather than single sit to standing.

In conclusion, the findings of the present study indicate that all three balance dimensions must be taken into consideration during training for the sit-to-stand activity, but to train for the stand-to-sit activity, the focus should be on improving ML balance and asymmetrical foot positioning should be recommended.

\section{REFERENCES}

1) Statistics Korea. The cause of death. 2015.

2) Kwakkel G, Kollen BJ, Wagenaar RC: Therapy impact on functional recovery in stroke rehabilitation: a critical review of the literature. Physiotherapy, 1999, 85: 377-391. [CrossRef]

3) Park S, Shin I: Meta-analysis of constraint-induced movement therapy in hemiplegic stroke patient in Korea. Phys Ther Kor, 2012, 19: 59-68. [CrossRef]

4) Yang YR, Chen YC, Lee CS, et al.: Dual-task-related gait changes in individuals with stroke. Gait Posture, 2007, 25: 185-190. [Medline] [CrossRef]

5) Lutzenberger C, Pfeiffer F: Analysis of hemiparetic gait by using mechanical models. Proc. AMAM, Montreal, 8-12 August (ThP-I-1), 2000.

6) Carr JH, Shepherd RB: Neurological rehabilitation: optimizing motor performance, 2nd ed. London: Churchill Livingstone, 2010, pp 95-119.

7) Yen SC, Schmit BD, Wu M: Using swing resistance and assistance to improve gait symmetry in individuals post-stroke. Hum Mov Sci, 2015 , 42: 212-224. [Medline] [CrossRef]

8) Titianova EB, Pitkänen K, Pääkkönen A, et al.: Gait characteristics and functional ambulation profile in patients with chronic unilateral stroke. Am J Phys Med Rehabil, 2003, 82: 778-786, quiz 787-789, 823. [Medline] [CrossRef]

9) Morris S, Morris ME, Iansek R: Reliability of measurements obtained with the Timed "Up \& Go" test in people with Parkinson disease. Phys Ther, 2001, 81: 810-818. [Medline] 
10) Burnfield JM, McCrory B, Shu Y, et al.: Comparative kinematic and electromyographic assessment of clinician- and device-assisted sit-to-stand transfers in patients with stroke. Phys Ther, 2013, 93: 1331-1341. [Medline] [CrossRef]

11) Carr JH, Ow JE, Shepherd RB: Some biomechanical characteristics of standing up at three different speeds: implications for functional training. Physiother Theory Pract, 2002, 18: 47-53. [CrossRef]

12) Roebroeck ME, Doorenbosch CA, Harlaar J, et al.: Biomechanics and muscular activity during sit-to-stand transfer. Clin Biomech (Bristol, Avon), 1994, 9: 235-244. [Medline] [CrossRef]

13) Boukadida A, Piotte F, Dehail P, et al.: Determinants of sit-to-stand tasks in individuals with hemiparesis post stroke: a review. Ann Phys Rehabil Med, 2015, 58: 167-172. [Medline] [CrossRef]

14) Lowry KA, Sejdic E, Brach JS: Acceleration-based gait analysis: accelerating mobility assessment in older adult. Aging Health, 2013, 9: 465-467. [CrossRef]

15) Chen HB, Wei TS, Chang LW: Postural influence on Stand-to-Sit leg load sharing strategies and sitting impact forces in stroke patients. Gait Posture, 2010, 32: 576-580. [Medline] [CrossRef]

16) Silva PF, Quintino LF, Franco J, et al.: Measurement properties and feasibility of clinical tests to assess sit-to-stand/stand-to-sit tasks in subjects with neurological disease: a systematic review. Braz J Phys Ther, 2014, 18: 99-110. [Medline] [CrossRef]

17) Osada Y, Yamamoto S, Fuchi M, et al.: Sit-to-walk task in hemiplegic stroke patients: relationship between movement fluidity and the motor strategy in initial contact. J Jpn Phys Ther Assoc, 2015, 18: 7-14. [Medline] [CrossRef]

18) Park G, Woo Y: Comparison between a center of mass and a foot pressure sensor system for measuring gait parameters in healthy adults. J Phys Ther Sci, 2015, 27: 3199-3202. [Medline] [CrossRef]

19) Shin SS, Yoo WG: Effects of gait velocity and center of mass acceleration during turning gait in old-old elderly women. J Phys Ther Sci, 2015, 27: 1779-1780. [Medline] [CrossRef]

20) Janssen WG, Külcü DG, Horemans HL, et al.: Sensitivity of accelerometry to assess balance control during sit-to-stand movement. IEEE Trans Neural Syst Rehabil Eng, 2008, 16: 479-484. [Medline] [CrossRef] 